\title{
Mental and Social Health Atlas I in Saudi Arabia: 2007-08
}

\author{
A.A. Al-Habeeb ${ }^{7}$ and N.A. Qureshi
}

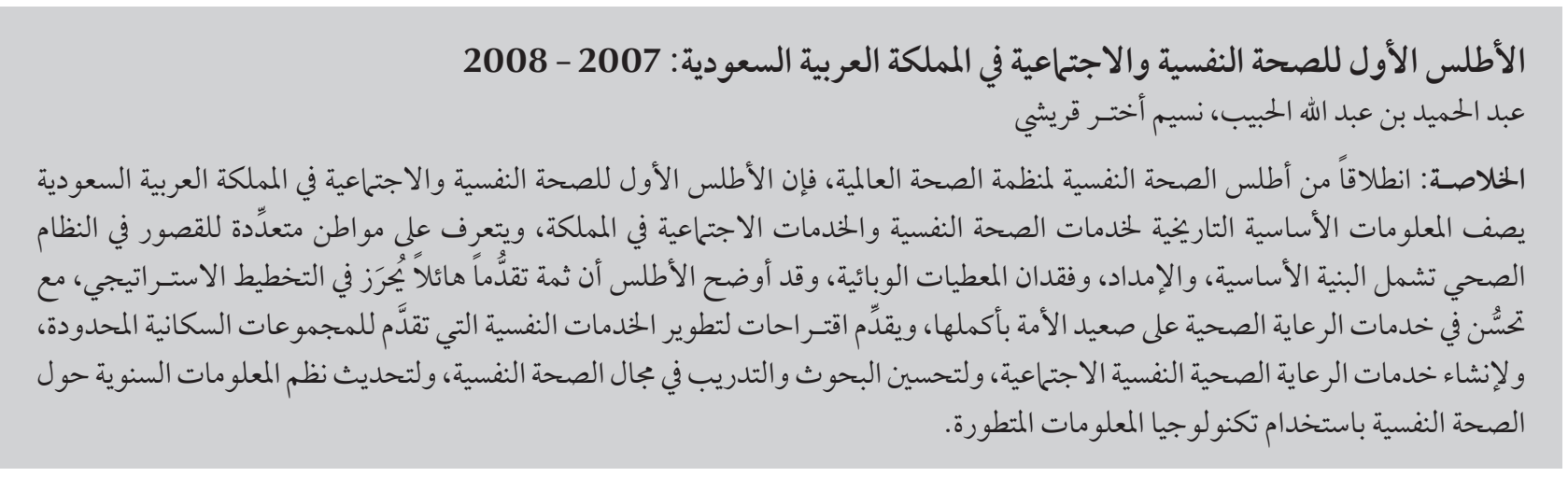

ABSTRACT Based on the World Health Organization's Mental Health Atlas, the first Mental and Social Health Atlas in Saudi Arabia describes the historical background of mental health and social services in the country and identifies several deficiencies in the system including infrastructure and logistics and lack of epidemiological data. There is now great progress in strategic planning for developing and improving mental health care services across the nation, with suggestions to develop psychiatric services for identified special populations, to establish community mental health care services, to improve research and training in mental health, and to update mental health annual information systems using advanced information technology.

\section{Mental and Social Health Atlas I in Saudi Arabia [Atlas 2007-2008 de la santé mentale et sociale en Arabie Saoudite] : 2007-2008}

RÉSUMÉ Fondé sur l'Atlas de la santé mentale de l'Organisation mondiale de la Santé, le Mental and Social Health Atlas I in Saudi Arabia [Atlas 2007-2008 de la santé mentale et sociale en Arabie Saoudite] passe en revue I'historique des services de santé mentale et des services sociaux dans le pays et identifie certaines lacunes du système : en termes d'infrastructures et de logistique, mais aussi le manque de données épidémiologiques. D'importants progrès ont été réalisés dans le domaine de la planification stratégique du développement et de l'amélioration des services de soins de santé mentale à travers le pays. Des suggestions ont été formulées pour mettre sur pied des services psychiatriques à l'attention de populations spécifiques, créer des services communautaires de soins de santé mentale, améliorer la recherche et la formation dans le domaine de la santé mentale et mettre à niveau les systèmes d'informations annuelles sur la santé mentale en utilisant des technologies informatiques de pointe.

${ }^{7}$ General Administration for Mental Health and Social Services, Ministry of Health, Riyadh, Saudi Arabia (Correspondence to N.A. Qureshi: qureshinaseem@live.com).

Received: 23/01/08; accepted: 01/07/08 


\section{Introduction}

In the year 2000, the Mental Health and Substance Abuse Division of the World Health Organization (WHO) launched the world Mental Health Atlas, an initiative which aimed to compile and synthesize mental health data from each member state of WHO $[1,2]$. In addition to distributing these data, WHO identified the unmet mental health and social needs of patients with mental health conditions across each country and recommended ways to improve the conditions of patients and their care-givers, especially through proper planning and investment in mental health [3]. The sources of data for the world Mental Health Atlas project were numerous but primarily the health ministries of each country. The Mental Health Atlas emphasized that, while it was important to address the many unmet needs of psychiatric populations worldwide, the challenges were greatest in low- and middleincome countries.

By 2005, however, there had been little improvement in the overall scenario of mental health care in developing countries. The evaluation of global progress made over the 5 years since the launch of the first world Mental Health Atlas revealed a dismal picture [3]. It showed that considerable improvements were needed, from infrastructure to resources, especially financial resources, in order to fully serve the most neglected psychiatric populations of the world.

By 2005, however, an evaluation of global progress made in the 5 years since the launch of the first world Mental Health Atlas revealed that there had been little improvement in the overall scenario of mental health care in developing countries [3]. It argued that considerable improvements were needed, from infrastructure to resources, especially financial resources, in order to fully serve the most neglected psychiatric populations of the world.

\section{Saudi Arabian Mental and Social Health Atlas I: goals and objectives}

Following the same concept as the WHO Mental Health Atlas, and based on a situational analysis, Saudi Arabia has developed its own Atlas, described in this paper, with the specific goal of describing the current state of mental health and social services in the nation. The rationale of the first Mental and Social Health Atlas was to collect and synthesize data and distribute it globally, with subsequent 4-year follow-up evaluations compatible with the 4-year national strategic plan for mental health services outlined by the General Administration for Mental Health and Social Services (GAMHSS) at the Ministry of Health $(\mathrm{MOH})$ in Riyadh. An evaluation report- to be included in the next edition of the Saudi Mental and Social Health Atlas I and compared with the WHO Atlas standards - will guide health authorities in planning and developing appropriate, focal point services for meeting the unmet needs of the psychiatric patient population in Saudi Arabia.

\section{Data collection mechanisms}

In order to collect relevant information from psychiatric care settings for the Atlas, 2 specially-designed, semistructured pro formas were faxed to all regional psychiatric hospitals and de-addiction units of the MOH. Any missing information in returned pro formas was completed by a social worker by telephone. $\mathrm{MOH}$ documents such as annual statistical reports, health indicators and other regularly published materials were also screened for mental health data. Data were abstracted from published materials of the Ministry of Social Affairs (MOSA), which collaborates with $\mathrm{MOH}$ in delivering combined services. A search was also made for published data in local medical journals, in addition to MEDLINE and WHO website searches.

In a related development, the $\mathrm{WHO}$ Assessment Instrument for Mental Health Systems (WHO-AIMS) is a new tool which collects essential information on the mental health services of a country or region and provides a baseline for monitoring change [4]. This tool also generates data on strengths and weaknesses to facilitate improvements in mental health services, including community services, and enables countries to develop evidenced-based mental health plans and to inform policies with clear baseline information and targets.

\section{Elements of the Saudi Arabian Mental and Social Health Atlas}

The components of the Saudi Arabian Mental and Social Health Atlas are sections on: a short historical background to mental health services in the country; mental health policies and legislation; budgeting mechanisms; community care; primary care psychiatry; rehabilitation centres; psychiatric beds; general hospital psychiatry; human resources; programmes for special populations; rehabilitation and day care centres; chronic patients; a 4-year national strategic plan; psychotropic drugs, pharmaceutical companies and mental health; information systems; discussion; and future directions and challenges.

\section{Historical background of mental health services in Saudi Arabia}

The first 250-bed psychiatric hospital in Saudi Arabia was opened in the city of Taif in the year 1952. Before that time there was no official recognition of psychiatric problems, and for public safety 
reasons mentally ill patients who were perceived as dangerous were kept locked in public buildings in the city of Mecca. By 1992, the Taif psychiatric hospital bed capacity had increased to 690 and emergency services and sub-specialty clinics were added. The second 36-bed hospital was established in Medina city in the year 1960. Within the next 4 decades, 18 more hospitals were opened in different regions, with current bed capacities ranging from 30 to 690. Most of these hospitals started in rented buildings with 30 to 50 beds and later moved to public buildings with bed capacities averaging around 100-200, with additional inpatient facilities to meet the increasing demands for mental health care. Three hospitals were planned for patients with drug abuse: Jeddah Al-Amal hospital (200 beds) and the Riyadh Al-Amal (428 beds) and Dammam Al-Amal (300 beds) psychiatric complexes which were integrated with psychiatric hospitals to serve both types of patients.

\section{Mental and social health policies}

All 20 hospitals have independently developed their own policies and procedures together with a quality assurance manual with job descriptions for all staff. With the help of mental health experts, GAMHSS collated these and, after approval by the health authorities, has recently issued a revised manual to ensure greater uniformity of policies and procedures across all psychiatric hospitals. This manual includes the following: organizational chart of the hospital according to its bed capacity; standards of human resources; comprehensive policies and procedures; filing systems; and national quality indicators. A comprehensive description of this manual (available upon request from the authors) is beyond the scope of the Mental and Social Health Atlas.

\section{Mental health legislation}

Despite the regulatory measures and protocols for preventing violence and suicide within and outside hospitals, there is a major regulatory vacuum due to the lack of an equivalent of the mental health act in Saudi Arabia. This contrasts with all other WHO member nations, who have their own mental health legislation (Table 1). However, a team of psychiatric consultants is currently preparing a legislative document to be submitted soon to the Ministerial Council for approval. Saudi Arabia would then have its own mental health act, sensitive to its unique sociocultural and Islamic values.

\section{Mental health budget and financing}

The annual budget of the $\mathrm{MOH}$ has been increasing annually and 23 billion Saudi riyals was allocated for the year 2006-07.MOH finances are controlled by its financial section in consultation with the Ministry of Finance. With the exceptions of some directorates, such as those concerned with training and scholarships, no finances are earmarked for GAMHSS. This contrasts with the $\mathrm{MOH}$ of other countries, which specify a separate budget for mental health ( $\mathrm{Ta}$ ble 2). In Saudi Arabia, all financial requests from hospitals are directed to the $\mathrm{MOH}$ through regional health directorates, which are approved by the finance department. GAMHSS also forwards their requests to the finance department through the Assistant Deputy Minister for Curative Medicine. Though it is desirable to estimate what proportion of the annual $\mathrm{MOH}$ budget is spent on mental health services in Saudi Arabia,

\begin{tabular}{|c|c|c|c|c|c|c|c|c|}
\hline \multirow[t]{2}{*}{ Theme } & \multicolumn{7}{|c|}{$\%$ of countries } & \multirow[b]{2}{*}{ Saudi Arabia } \\
\hline & World & Africa & Americas & $\begin{array}{c}\text { Eastern } \\
\text { Mediterranean }\end{array}$ & Europe & $\begin{array}{l}\text { South-East } \\
\text { Asia }\end{array}$ & $\begin{array}{l}\text { Western } \\
\text { Pacific }\end{array}$ & \\
\hline Mental health policy & 59.5 & 47.8 & 64.5 & 68.2 & 67.3 & 70.0 & 48.1 & Yes \\
\hline Substance abuse policy & 69.4 & 52.2 & 71.0 & 81.0 & 85.7 & 80.0 & 53.8 & Yes \\
\hline $\begin{array}{l}\text { National mental health } \\
\text { programme }\end{array}$ & 69.7 & 73.9 & 80.6 & 86.4 & 55.1 & 80.0 & 59.3 & Yes \\
\hline Mental health legislation & 75.3 & 71.1 & 67.9 & 57.1 & 91.7 & 70.0 & 76.0 & $\begin{array}{c}\text { Under } \\
\text { development }\end{array}$ \\
\hline \multicolumn{9}{|l|}{$\begin{array}{l}\text { Programmes for special } \\
\text { populations }\end{array}$} \\
\hline Children & 59.9 & 37.8 & 74.2 & 68.2 & 77.1 & 60.0 & 42.3 & $\begin{array}{c}\text { Under } \\
\text { development }\end{array}$ \\
\hline Elderly & 47.8 & 17.8 & 66.7 & 54.5 & 62.5 & 60.0 & 38.5 & $\begin{array}{c}\text { Under } \\
\text { development }\end{array}$ \\
\hline Annual reporting system & 72.9 & 52.3 & 67.7 & 75.0 & 89.9 & 90.0 & 74.1 & Yes \\
\hline
\end{tabular}




\begin{tabular}{|c|c|c|c|c|c|c|c|c|}
\hline \multirow[t]{2}{*}{ Theme } & \multicolumn{8}{|c|}{$\%$ of countries } \\
\hline & World & Africa & Americas & $\begin{array}{c}\text { Eastern } \\
\text { Mediterranean }\end{array}$ & Europe & $\begin{array}{l}\text { South-East } \\
\text { Asia }\end{array}$ & $\begin{array}{l}\text { Western } \\
\text { Pacific }\end{array}$ & Saudi Arabia \\
\hline $\begin{array}{l}\text { Specified budget for } \\
\text { mental health }^{a}\end{array}$ & 72.0 & 62.2 & 92.6 & 80.0 & 72.3 & 66.7 & 63.0 & Not specified \\
\hline Tax-based payments & 60.2 & 53.9 & 66.7 & 66.6 & 50.0 & 70.0 & 73.1 & Yes \\
\hline $\begin{array}{l}\text { Out-of-pocket } \\
\text { payments }\end{array}$ & 16.6 & 35.9 & 13.3 & 22.2 & 0.0 & 30.0 & 11.5 & $\begin{array}{l}\text { Yes, only for } \\
\text { buying drugs if } \\
\text { not available }\end{array}$ \\
\hline Disability benefits & 75.4 & 46.5 & 87.1 & 75.0 & 98.0 & 90.0 & 61.5 & Yes \\
\hline
\end{tabular}

aProportion of total health budget.

no such figures are presently available. GAMHSS has already requested a separate budget for mental health services from the relevant health and financial authorities. Some hospitals, such as Riyadh Al-Amal psychiatric complex, are controlled by $\mathrm{MOH}$ autonomous organizations, which have their own financial mechanisms.

\section{Community mental health care}

Unlike industrialized countries there are limited community mental health care (CMHC) services for mental patients in Saudi Arabia (Table 3). Besides private psychiatric services, there exist welldeveloped out- and inpatient services in psychiatric hospitals. A CMHC service would comprise community-based residential and non-residential services and $\mathrm{CMHC}$ centres that provide a variety of therapies for mental patients. In the great majority of cases, the lack of services in the community in Saudi Arabia is the reason why patients with chronic mental illnesses are resident in mental hospitals. Developing CMHC is therefore a priority. This can be achieved by establishing CMHC centres and developing primary health care (PHC) psychiatry, residential houses, day care units, rehabilitation centres and case management programmes. Voluntary organizations and self-help groups should also be established. The $\mathrm{MOH}$ is forming the National Committee for Caring Psychiatric Patients and their Families with a coordination centre at GAMHSS. Regional committees will also be formed for serving patients and their families. The mechanisms for developing CMHC are included in the 4-year national strategic plan.

\section{Mental health in primary care}

There are a total of 1905 PHC centres in Saudi Arabia. Following the evidencebased recommendations of WHO to integrate mental health into $\mathrm{PHC}$, there have been substantial developments globally aiming to deliver mental health services via PHC. Besides other mechanisms, training of general practitioners (GPs) in clinical psychiatry is considered the most significant step in facilitating this integration. Therefore, psychiatric courses for GPs have been organized regularly at regional as well as national level, along with training of trainers schemes (Table 3). Some

\begin{tabular}{|c|c|c|c|c|c|c|c|c|}
\hline \multirow[t]{2}{*}{ Theme } & \multicolumn{8}{|c|}{$\%$ of countries } \\
\hline & World & Africa & Americas & $\begin{array}{c}\text { Eastern } \\
\text { Mediterranean }\end{array}$ & Europe & $\begin{array}{l}\text { South-East } \\
\text { Asia }\end{array}$ & $\begin{array}{l}\text { Western } \\
\text { Pacific }\end{array}$ & Saudi Arabia \\
\hline Community based-care & 63.4 & 54.3 & 71.0 & 54.3 & 72.3 & 50.0 & 66.7 & Almost none \\
\hline $\begin{array}{l}\text { Mental health care in } \\
\text { primary health care }\end{array}$ & 87.0 & 82.6 & 96.8 & 77.3 & 95.9 & 80.0 & 77.8 & Yes \\
\hline 1. Treatment facilities & 59.1 & 56.5 & 66.7 & 50.0 & 65.3 & 44.4 & 55.6 & $\begin{array}{c}\text { Only referral } \\
\text { of patients \& } \\
\text { counselling }\end{array}$ \\
\hline 2. Training & 59.0 & 53.3 & 41.9 & 77.3 & 61.7 & 90.0 & 55.6 & Yes \\
\hline $\begin{array}{l}\text { Therapeutic drugs } \\
\text { policy/essential } \\
\text { list of drugs }\end{array}$ & 88.4 & 95.7 & 86.7 & 95.2 & 79.2 & 100.0 & 84.6 & Yes \\
\hline
\end{tabular}


studies of PHC mental health issues have been published from Saudi Arabia [5-7]. Despite this, mental health services at $\mathrm{PHClevel}$ are still very limited in Saudi Arabia. Trained GPs treat only minor mental disorders via counselling, and difficult cases are still referred to the secondary level. The availability of essential psychotropic drugs at PHC centres is yet to be approved by the $\mathrm{MOH}$. The new integrated strategies include prevention of relapse and early detection of mental disorders in PHC by suitable screening scales, which will be used by trained psychologists and social workers. Screening patients with psychiatric problems in $\mathrm{PHC}$ is itself a highly important clinical exercise.

\section{Psychiatric beds}

There are 2886 beds in 20 psychiatric hospitals in Saudi Arabia (Table 4). The bed occupancy (total number of inpatients/number of beds $\times 100)$ in most psychiatric hospitals is more than $100 \%$ throughout the year (ideal figure $85 \%)$. It is a source of many problems, such as inadequate services and demoralization of administrative and clinical staff. Taking the Saudi population to be 23 million, the bed ratio per 10000 population is 1.25 . This figure is higher than other countries of the Eastern Mediterranean Region, but lower than that of North America (3.3) and Europe (8.7). However, within the next 4 years the total number of beds is expected to reach 1.6 per 10000 . The additional beds will be established only in general hospitals.

\section{General hospital psychiatry}

The total number of $\mathrm{MOH}$ general and specialist hospitals is 218 . The other non-MOH government $(n=38)$ and private hospitals $(n=123)$ total 161 . There are 44 psychiatric clinics, but no fixed beds for patients requiring admission to $\mathrm{MOH}$ general hospitals, which are a transit route for serious mentally ill patients. Certainly more psychiatric clinics and beds need to be established in general hospitals. Notably, consultation-liaison psychiatry is being developed in some tertiary hospitals. This needs the attention of hospital administrators and mental health teams to draft specific guidelines and procedures for these clinics, together with plans for establishing both more consultationliaison psychiatry and inpatient services in general hospitals.

\section{Human resources}

The total number of psychiatrists, psychologists, social workers and nurses per 100000 population in psychiatric hospitals is $0.89,0.83,0.94$ and 9.5 respectively (Table 4). However, these may not strictly match WHO definitions. For example, as for psychologists and social workers, many nurses initially assigned to hospitals do not have any experience in psychiatry but have only completed the relevant continuing medical education (CME) courses. Notably most psychologists and social workers do not have postgraduate degrees and have very limited clinical orientation, which further restricts their clinical input. They need advanced training in universities, with more focus on clinical exercises.

\section{Programmes for special populations}

Children with mental health problems have special needs and accordingly require tailored services (Table 1). Elderly people with dementia often have physical diseases require multiple medication and other therapies. Women with postpartum mental problems also have special psychiatric needs. There is

\begin{tabular}{|c|c|c|c|c|c|c|c|c|}
\hline \multirow[t]{2}{*}{ Theme } & \multicolumn{8}{|c|}{ Rate per population } \\
\hline & World & Africa & Americas & $\begin{array}{c}\text { Eastern } \\
\text { Mediterranean }\end{array}$ & Europe & $\begin{array}{l}\text { South-East } \\
\text { Asia }\end{array}$ & $\begin{array}{l}\text { Western } \\
\text { Pacific }\end{array}$ & $\begin{array}{c}\text { Saudi } \\
\text { Arabia }^{\mathrm{b}}\end{array}$ \\
\hline $\begin{array}{l}\text { Psychiatric beds } \\
\quad(\text { per } 10000)^{\mathrm{a}}(n=2886)\end{array}$ & 1.6 & 0.34 & 3.3 & 0.79 & 8.70 & 0.33 & 0.98 & 1.25 \\
\hline $\begin{array}{l}\text { Qualified psychiatrists } \\
\text { (per } 100000)(n=205)\end{array}$ & 1.0 & 0.05 & 1.6 & 0.95 & 9.00 & 0.21 & 0.28 & 0.89 \\
\hline $\begin{array}{l}\text { Psychiatric nurses } \\
\quad(\text { per } 100000)(n=2187)\end{array}$ & 2.0 & 0.20 & 2.7 & 0.50 & 27.50 & 0.16 & 1.10 & 9.50 \\
\hline $\begin{array}{l}\text { Psychologists } \\
\quad \text { (per } 100 \text { 000) }(n=191)\end{array}$ & 0.4 & 0.05 & 2.8 & 0.20 & 3.00 & 0.02 & 0.03 & 0.83 \\
\hline $\begin{array}{l}\text { Psychiatric social workers } \\
\text { (per } 100 \text { 000) }(n=216)\end{array}$ & 0.3 & 0.04 & 1.9 & 0.40 & 2.35 & 0.05 & 0.13 & 0.94 \\
\hline
\end{tabular}

a Includes psychiatric and addiction unit beds.

${ }^{b}$ Total population 23 million. 
a shortage of manpower in these subspecialties in Saudi Arabia and services are very limited. Geriatric patients with multiple diseases consult medical and PHC clinics, and for behavioural problems they are mostly evaluated by adult rather than specialist geriatric psychiatrists. Those elderly patients who, in rare cases, are rejected by their families are admitted to geriatric homes related to the MOSA. In emergency cases, they are referred to the nearest hospital. Medical internists and psychiatrists also visit geriatric patients for regular follow-up. Children with psychiatric disorders are evaluated in a range of different health settings. There is a priority need to develop child and adolescent and geriatric psychiatric services in Saudi Arabia. Our 4-year national strategic plan includes training of selected psychiatrists in both subspecialties.

During the postpartum period some women are at risk of developing depression, anxiety disorders and acute toxic psychosis. The maternal and child hospitals in Saudi Arabia are integrated with mental health hospitals through referrals. Postpartum patients with mental disorders are now examined by psychiatrists with appropriate treatment interventions. Our 4-year national strategic plan aims to establish 1 child psychiatric clinic in each regional maternal and child hospital. Notably, some clinics are already established, for example in Buraidah maternal and child hospital.

\section{Rehabilitation and day care centres}

There are 36 rehabilitation and day care centres (RDCCs) for patients with intellectual disabilities, including physical disabilities, all under the financial support of MOSA, which also provide services to orphans and juvenile criminals. People with mild/moderate intellectual disabilities causing behavioural problems are managed in day care units with follow-up visits. Children with severe/profound intellectual disabilities are mostly institutionalized in RDCCs with regular visits from their parents. Depending on behavioural problems and comorbid conditions, the patients are prescribed psychotropic and antiepileptic drugs, and non-medical interventions [8].

Inpatients in RDCCs who develop episodically acute excitement and medical problems are immediately referred to psychiatric/medical treatment centres for management. Disturbed patients are mostly admitted temporarily to psychiatric wards. Psychotropic drugs for RDCC inpatients are supplied by the $\mathrm{MOH}$. While the services offered are not assessed for quality, RDCCs offer excellent services for outpatients and provide relief to family care-givers. Many tailored programmes are provided, including carpentry, sewing, agriculture, painting and electrical, computer and electronics skills $[9,10]$. It would be wise to explore the attitudes of health providers and the public towards children with intellectual disabilities to help in further planning innovative services, with strategies such as media campaigns to destigmatize these children.

\section{Patients with chronic psychiatric disorders}

A patient with a staying more than 6 months in hospital is considered a longstay patient. Our survey showed that the total number of chronic patients in all psychiatric hospitals was 1120 and most of them $(n=1099)$ were of Saudi Arabian nationality; males were 873 . Most chronic patients $(n=762)$ were in the age band 21-50 years, 274 were over 50 years and 7 were under the age of 20 years. The main reasons for longstay care were refusal by care-givers $(n$ $=601)$, unstable condition $(n=167)$, need for rehabilitation $(n=164)$, seriousness of patients' condition $(n=113)$ and other $(n=75)$. Lack of community services, stigma and absence of half-way homes were other factors.
Patients with chronic drug addiction

A patient with drug abuse staying more than 3 months in a de-addiction unit was defined as a long-stay patient. The total number of chronic patients identified in our survey was 51. Most of them were males of Saudi Arabian nationality $(n=50)$. A majority of them $(n=48)$ were between $21-50$ years of age. They were long-stay patients due to recommendations of the treatment team ( $n$ $=11$ ), orders from higher authorities $(n=10)$, refusal of care by the family $(n$ $=4$ ) or dual diagnosis (i.e. drug abuse plus schizophrenia or other mental disorder) $(n=26)$. Many of them $(n=21$, $40 \%$ ) stayed more than 7 months.

The 2 Al-Amal complex hospitals have integrated in- and outpatient treatment services including good quality psychosocial treatment centres for psychiatric and drug abuse patients. In addition, antismoking clinics offer smokers a range of comprehensive services for quitting smoking. More details about patients' annual visits, inpatient admissions and human resources can be found elsewhere [11].

\section{Four-year national strategic plan}

Matching international trends, GAMHSS has drafted the first national strategic plan for improving and developing psychiatric services in Saudi Arabia. This 4-year national strategic plan (available upon request from the authors) was approved by health authorities and was distributed to all psychiatric hospitals for implementation in January 2007. Progress is monitored by GAMHSS. The regional administration centres for mental health services are responsible for its implementation and communicate with GAMHSS in case of any difficulties. The regional health directorates will forward the mid-year report to GAMHSS. 
The 8 main goals which define mechanisms for effective implementation of the 4-year national strategic plan are: (1) development of both modern infrastructure and competent manpower; (2) improving the quality and quantity of mental health services; (3) expansion of de-addiction services; (4) developing innovative continuing medical education programmes; (5) developing research units in psychiatric hospitals with the aim of conducting applied research (10 national registries for important psychiatric disorders and related issues such as electroconvulsive therapy and neuroleptic malignant syndrome were established to provide data for analysis); (6) establishing national quality indicators and professional development in child and adolescent, geriatric, addiction, forensic and primary care psychiatry and consultationliaison psychiatry subspecialties; (7) development of social service units in general and specialist hospitals; and (8) promoting the defined roles of GAMHSS in overall planning and development of mental health services throughout Saudi Arabia.

\section{Psychotropic medications}

Local pharmaceutical companies have engaged in several mental health activities in Saudi Arabia, including supplying psychotropic drugs at reasonable cost to governmental and nongovernmental organizations that distribute them through medical supply divisions to all mental health settings. Pharmaceutical companies have also financially sponsored CME programmes for mental health professionals at the regional, national and international levels. There is an impressive direct and indirect impact of these programmes on the quality of mental health services offered to mental health consumers.

The Saudi MOH drug formulary has a section on drugs acting on the central nervous system, with 10 subcategories [12], and the list of medications is reviewed every year. GAMHSS recommends to $\mathrm{MOH}$ which psychotropic drugs should to be added to or deleted from the drug formulary, after discussions with members of the psychotropic drug committee.

\section{Mental health annual information systems}

A mental health annual information system allows for data collection, analysis and synthesis for informing 2 important end-users: decision-makers and the personnel who deliver services to mental health care consumers. Almost all psychiatric hospitals have both manual and computerized data collection mechanisms, including patient records, but data analysis, to inform the process of decision-making, is not done in many hospitals including those in the private sector. However, some annual reports on health statistics, including mortality data, are published by $\mathrm{MOH}$. Most regional psychiatric hospitals also prepare an annual report. However, the impact of such hospital reports on clinical practice, policy and decision-making has yet to be evaluated.

\section{Comments}

Over the past 5 decades, there has been slow but steady progress in the development of mental health services in Saudi Arabia. The infrastructurefacilities for inpatients have begun to improve over the past 10 years. The remaining outdated rented hospital buildings are being be replaced by modern hospitals. The policies approved by health authorities will streamline the delivery of good quality services to mental patients. This draft of the Mental and Social Health Atlas will be presented for a roundtable discussion in a workshop to be organized by GAMHSS in coordination with WHO
Regional Office for the Eastern Mediterranean. Once approved by the Council of Ministers of Saudi Arabia the Mental and Social Health Atlas will be used to further regulate mental health and forensic services, including development of targeted services for patients who need maximum security wards, which are currently lacking in Saudi Arabia. Mental patients who commit major crimes are mostly kept in prisons.

Currently CMHC and PHC psychiatric services are completely lacking in Saudi Arabia. Within the next 4 years, relevant services will be established uniformly across all regions. This development will reduce the huge burden felt by psychiatric hospitals and will also match the international focus on CMHC services. The $\mathrm{MOH}$ will focus mainly on developing CMHC centres, residential homes, CMHC teams and special services for crisis prevention. Furthermore, there should be a linkage between community consultation-liaison psychiatry services, including PHC psychiatry and psychiatric hospitals. It is known that some mental patients consult religious faith healers, who use untested interventions, and efforts should be made to integrate these healers into the mainstream mental health systems [13].

It is to be hoped that a budget for the entire mental health services will eventually be allocated separately to GAMHSS. The advantage of this would be more focused expenditures on mental health services development, including CMHC centres, infrastructural improvements, increased human resources and organization of CME for improving the skills of professionals including GPs and nurses.

As regard psychiatric beds and the number of mental health professionals, the current situation is improving. GAMHSS has been focusing on developing professionals through CME programmes in several subspecialties including clinical psychology and sociology. There is also a great emphasis on developing in- and outpatient mental 
health services in general hospitals that may further increase the supply of psychiatric beds and human resources. The bed capacity of psychiatric hospitals is planned to remain the same; however, $\mathrm{CMHC}$ services need to be developed rapidly.

Homes and day care centres for children with intellectual disabilities need appropriate programmes to enhance the quality of life of these children. Documents from MOSA suggest that, while specific programmes including medication for such children are in place, that the impact of these on patients is not clear. This area needs further action research.

The poor services for chronic mental health patients need to be addressed by proper development of CMHC in order to integrate chronic mental patients into the community. For example, there is a priority need to establish residential homes for this population which should be supervised by a CMHC team. The roles for care-givers and other family members in these homes are much greater than traditionally believed.

The unavailability of psychotropic drugs in psychiatric care settings is a source of frustration both to prescribers and patients and improving their availability is an important goal of the $\mathrm{MOH}$. Any changes to a patient's drug prescription risk causing psychological upset to the patient, increased costs, poor adherence, relapses and even hospitalization. Newer psychotropic drugs with a better clinical profile should be added regularly to the $\mathrm{MOH}$ drug formulary along with the deletion of older drugs. Notably, there is a need to develop an adverse effects reporting system, to conduct pharmacoepidemiological research and to train physicians in rational electronic prescribing systems that might prevent medication errors and also rationalize patient management. Finally, mental health annual information systems in all psychiatric hospitals should be updated regularly in order to realize their potential for improving decisionand policy-making and annual reporting. The information collected might also be valuable for wider dissemination in scientific journals and for comparative studies.

\section{Future directions and challenges}

Besides drafting the second Saudi Arabian Mental and Social Health Atlas, the main focus of GAMHSS within the next 4 years will be the following:

- To follow-up the implementation of the 4-year national strategic plan for developing and improving mental health care services across the nation.
- To develop psychiatric services for identified special populations.

- To establish CMHC services including PHC psychiatry and consultationliaison psychiatry in general hospitals.

- To sustain CME programmes for professional development in several subspecialties.

- To help boost research in mental health settings.

- To update mental health annual information systems using advanced information technology.

WHO-AIMS is a new instrument for collecting important information on mental health services for several purposes, including monitoring of changes, drafting reform policies and developing mental health plans from baseline information. This tool would be a useful resource for drafting the second edition of the Saudi Arabian Mental and Social Health Atlas and also for monitoring progress and improvements in mental health services.

\section{Acknowledgements}

The authors would like to express sincere thanks to those who helped in the production of this document. We also acknowledge the support of AstraZeneca in particular in producing this atlas.

\section{References}

1. Atlas: mental health resources in the world. Geneva, World Health Organization, 2001.

2. Saraceno B, Saxena S. Mental health resources in the world: results from Project Atlas of the WHO. World psychiatry, 2002, 1:40-4.

3. Saxena S et al. World Health Organization's Mental Health Atlas 2005: implications for policy development. World psychiatry, 2006, 5:179-84.

4. WHO report on mental health systems of selected low- and middleincome countries. Geneva, World Health Organization, 2009.

5. Qureshi NA et al. Integration of mental health care into primary care: preliminary observations of continuing implementation phase. Saudi medical journal 2001, 22:899-906.

6. Qureshi NA et al. General practitioners' pre- and post-training psychiatric knowledge and attitude towards psychiatry. Neurosciences journal, 2004, 9:287-94.
7. Qureshi NA et al. Effectiveness of training programmes directed at general practitioners for enhancing their psychiatric knowledge. Education for health journal, 2006, 19:52-60.

8. Rehabilitation centers: report. Riyadh, Saudi Arabia, Ministry of Social Affairs, 2007.

9. Day care centers: report. Riyadh, Saudi Arabia, Ministry of Social Affairs, 2007.

10. Welfare and development: report. Riyadh, Saudi Arabia, Ministry of Social Affairs, 2007.

11. 7th annual report. Dammam, Saudi Arabia, Al-Amal Psychiatric Complex, 2006.

12. Saudi national formulary 2006. Riyadh, Saudi Arabia, Ministry of Health, 2006.

13. Qureshi NA et al. Traditional cautery among psychiatric patients in Saudi Arabia. Transcultural psychiatry, 1998, 35:7583. 